Article

\title{
The Role of Parents in Problematic Internet Use among US Adolescents
}

\author{
Amy Bleakley ${ }^{1, *}$, Morgan Ellithorpe ${ }^{1}$ and Daniel Romer ${ }^{2}$ \\ ${ }^{1}$ Annenberg School for Communication, University of Pennsylvania, Philadelphia, PA 19104, USA; \\ E-Mails: ableakley@asc.upenn.edu (A.B.), mellithorpe@asc.upenn.edu (M.E.) \\ ${ }^{2}$ Annenberg Public Policy Center, University of Pennsylvania, Philadelphia, PA 19104, USA; \\ E-mail: dromer@asc.upenn.edu \\ * Corresponding author
}

Submitted: 7 December 2015 | Accepted: 25 February 2016 | Published: 16 June 2016

\begin{abstract}
The internet has transformed the way youth communicate, learn, and network, with implications for their broader social, psychological, and physical health and well-being. With the technological capability of accessing the internet from anywhere, at any time, paired with the enormous variety of internet activities in which youth engage-from social networking to chatting to streaming videos to playing games to watching television content-instances of problematic internet behavior have emerged. We conducted an online national survey of 629 US adolescents ages 12-17 years old and a matching survey of one of their parents. We investigated the relationship between problematic internet behavior and parental monitoring, parental mediation of internet use, and parental estimates of their adolescent's time spent using computers. Analyses showed that problematic internet use was associated with less parental monitoring and parental mediation and poorer parental relationships. Adolescents that spent a lot of time on the computer were also more likely to engage in problematic internet use. Although we cannot determine the direction of the relationships, results support the important role of parents in adolescents' problematic internet use.
\end{abstract}

\section{Keywords}

adolescents; computer time; internet addiction; parental mediation; parental monitoring; problematic internet use

\section{Issue}

This article is part of the issue "Adolescents in the Digital Age: Effects on Health and Development", edited by Dan Romer (University of Pennsylvania, USA).

(C) 2016 by the authors; licensee Cogitatio (Lisbon, Portugal). This article is licensed under a Creative Commons Attribution 4.0 International License (CC BY).

\section{Introduction}

Youth are avid users of the internet. According to the Pew Research Center, 95\% of adolescents (ages 12-17 years) and young adults (ages 18-29) in the United States are online, which is a figure that has for the most part remained stable for nearly a decade (Madden, Lenhart, Duggan, Cortesi, \& Gasser, 2013). Additionally, differences in internet access based on income and race are not as steep as previously noted, especially among younger adults (Smith, 2014). Among youth in the United States, estimates of time spent on a computer, but not necessarily online, range from an average of 1.4 hours per day among 15-18 year old youth (Rideout, Foehr, \& Roberts, 2010) to 2.6 hours per day among youth ages 12-17 years (Bleakley, Vaala, Jordan, \& Romer, 2014). And finally, mobile technologies like smartphones have made the internet more accessible, as ownership of such devices among youth has increased in recent years (Madden et al., 2013).

With the internet as a prominent and accessible fixture in the lives of youth, one concern is that young people may use, or overuse, the internet is ways that could be described as "problematic." With the technological capability of accessing the internet from anywhere, at any time, paired with the enormous variety of internet activities in which youth engage-from social networking to chatting to streaming videos to playing games to watching television content-instances of problematic internet behavior have emerged. The term 
"internet addiction" is often used to describe compulsive internet use in the same way as clinically diagnosable behavioral and substance-use addictions. However, there is widespread disagreement about basic terminology and definitions pertaining to the idea of internet addiction, and whether it is a diagnosable condition or disorder (Mitchell, 2000). Additionally, the inclusion of "Internet Gaming Disorder" in the DSM-5 (American Psychiatric Association, 2013) has done little to clarify the various conceptualizations of problematic internet use, often referred to interchangeably as internet addiction, gaming addiction, cyberspace addiction, online addiction, net addiction, Internet addicted disorder, and high Internet dependency (Douglas et al., 2008).

Using data from a national survey of US adolescents and their parents, we investigated problematic internet behavior and its association with parental factors and the home media environment. We describe the extent to which indicators of problematic internet use are reported, and estimate how parental influence is associated with these signs of problematic internet use. The parental factors we consider are parental monitoring, parental mediation of internet use, parent-teen relationship quality, and parent perception of their teen's time spent using computers.

\section{Problematic Internet Use}

Competing definitions and theoretical approaches, and inconsistent measurement, have led to a range of estimates on the prevalence of pathological internet use (Moreno, Jelenchick, Cox, Young, \& Christakis, 2011), and controversy surrounds the meaning of the classification. In particular, some argue that rather than being a unique disorder, it is more useful to consider it a coping mechanism for other problems (e.g., Davis, 2001). Others question whether the behavior is truly an addiction to the internet per se, or merely a convenient outlet for behavior that would otherwise occur offline, such as gambling, gaming, or use of pornography (e.g., Griffiths, 2005).

One model of problematic internet use introduced by Davis (2001) uses a cognitive-behavioral approach that labels the behavior as pathological internet use rather than internet addiction. In particular, the model suggests that persons suffering from depression, anxiety, or substance use disorders may retreat to the internet as a way of coping with their disorder, especially as a substitute for offline social activity. Furthermore, certain maladaptive cognitions that accompany these disorders can enhance attraction to the internet, such as beliefs of low self-worth that incline the user to retreat to more satisfying online forms of interaction with persons unknown to the individual, such as gaming or certain types of social networking. Social isolation and lack of social support in the offline world, often associated with other disorders, are likely to increase attraction to such online forms of social interaction (Davis, 2001).

Regardless of what draws individuals to engage in it, however, problematic internet use is associated with negative interpersonal and psychosocial outcomes (Caplan \& High, 2011). In adolescents and emerging adults, specifically, it has been found to be associated with increased rates of attention deficit hyperactivity disorder (Yoo et al., 2004), sleep disturbances and excessive daytime sleepiness (Choi et al., 2009), problematic alcohol use (Ko et al., 2008), and impaired academic performance (Jacobsen \& Forste, 2011; Kubey, Lavin, \& Barrows, 2001). Therefore, understanding the antecedents and correlates of problematic internet use could serve not only to reduce the proximate behavior, but also to ameliorate these other issues as well.

Despite these competing definitions, two studies on internet behavior among adolescents from Europe are worth mentioning because of their cross-national samples. In a study by Durkee et al. (2012), which included participants $(n=11,956)$ with a mean age of 14.9 (SD 0.89 ) across 11 European countries, the overall prevalence of what they called problematic internet use was 4.4\% (Durkee et al., 2012). Estimates varied by gender and country, with boys exhibiting greater problematic internet use than girls. A later study by Tsitsika et al (2014) found $1 \%$ of adolescent participants ( $n=13,284$ from seven European countries) exhibiting internet addiction according to criteria based on the Internet Addiction Test (IAT,Young, 1998), with $12.7 \%$ exhibiting problematic internet behavior. The authors concluded that $13.9 \%$ showed "dysfunctional" internet behavior, defined as the sum of the two IAT classifications. Similar to the Durkee et al (2012) study, differences were found in rates by gender and country, once again with boys displaying greater internet addiction than girls. In the present study, we characterize a sample of adolescents from the United States, ages 12-17 years, with regard to the extent of their problematic internet use.

\section{Parental Influence on Internet Use}

The role that parents play in adolescents' problematic internet use is an important influence to consider. This is the case both in regard to the environment in which problematic use may occur and in identifying potential points of intervention. Few studies have examined parental context as a correlate of problematic or addictive internet behavior. Findings in both Asian (Chng, Li, Liau, \& Khoo, 2015) and European (Siomos et al., 2012) samples of adolescents exhibiting problematic internet use report less favorable relations with parents. Additionally, there is evidence that adolescents with less parental monitoring experience greater harassment online, such as receiving upsetting emails or instant messages and having rumors posted about them on social media (Khurana, Bleakley, Jordan, \& Romer, 2014). 
Parental monitoring/knowledge. Parental monitoring is considered to be a set of parenting practices or behaviors through which parents are aware of their adolescents' whereabouts, peers, and activities (Borawski, levers-Landis, Lovegreen, \& Trapl, 2003; Stattin \& Kerr, 2000). Studies on risk-taking and adolescent antisocial behavior consistently demonstrate that the amount of parental monitoring perceived by an adolescent is protective (Borawski et al., 2003; DiClemente et al., 2001; Kerr, Stattin, \& Burk, 2010; Li, Stanton, \& Feigelman, 2000) against engaging in risky behaviors such as unprotected sex (Borawski et al., 2003; Huebner \& Howell, 2003) as well as alcohol and drug consumption (DiClemente et al., 2001). However, there are challenges to validity of the parental monitoring construct, which some argue is actually measure of "parental knowledge" (Stattin \& Kerr, 2000) and not active parental efforts to track their child's activities. Also at issue is how parents come to obtain the knowledge about their adolescents that allows them to effectively "monitor": through child disclosure, parental solicitation, and/or parental control (e.g., rules and restrictions) (Racz \& McMahon, 2011). Studies have shown that parental knowledge is most likely a function of an adolescent's disclosure or other personality traits, and that it is parental knowledge rather than restrictive parental behavior that is associated with less problem behavior (Kerr et al., 2010). In this study we use the "parental monitoring" terminology to remain consistent with prior literature but recognize that our measures are better indicators of parental knowledge and not necessarily active parental surveillance.

Research pertaining to general parental monitoring of adolescent behavior and internet use has largely taken a risk-reduction perspective as well by focusing on problematic behaviors. For example, international studies have shown that parental monitoring and similar constructs (e.g., parent-child cohesion; parent involvement) are associated with lower rates of teen exposure to risky online content (i.e., sexual and violent content, gambling sites, and interaction with strangers (Cho \& Cheon, 2005) and teen internet addition (C.-H. Lin, S.-L. Lin, \& Wu, 2009; Xu, Turel, \& Yuan, 2012), but may be unrelated to cyberbulling or cyber-victimization (Aoyama, Barnard-Brak, \& Talbert, 2012; Mesch, 2009). Limited research has examined relationships between parental monitoring and youth online behavior with regard to time spent online or on specific internet activities that are not necessarily risky. One analysis by Sun and colleagues (2005) showed that parental monitoring was related to US adolescents' internet use at home but not at school. Given documented concerns among parents about the amount of time their children spend online (Livingstone \& Bober, 2004) parental monitoring may be related to lower rates of teen computer use overall as well as time spent in specific online activities (Vaala \& Bleakley, 2015). Given prior research on the protective effects of parental monitoring on health risk behaviors and media behavior, we expect that adolescents who perceive greater parental monitoring will be less likely to report indicators of problematic internet use.

Parental mediation. In the youth and media literature, parental mediation has three distinct forms: (1) active mediation refers to parent-child discussion about media content; (2) restrictive mediation includes parents' rule-setting or limiting the time or content of children's media use; and (3) co-viewing occurs when parents view or use media together with children (Nathanson, 2002). Mediation is different from parental monitoring/knowledge in that it is specific to media activities (as opposed to monitoring, which is concerned with all behavior). Each of these mediation behaviors has evidenced varying patterns of influence on children's media use and the effects of media content, depending on the nature and context of the parental mediation (e.g. co-viewing TV can increase negative effects of unfavorable content if children perceive parents to be condoning the onscreen behaviors ( $\mathrm{Na}$ thanson, 2002)). Although the roots of the framework are in television research, parental mediation behaviors have been re-conceptualized more recently to include mediation of children's and adolescents' newer digital media use as well (Clark, 2009; Livingstone \& Helsper, 2008). Forms of internet mediation include discussion of online content, the rules parents set, and monitoring and co-use behaviors that could directly constrain the amount of time adolescents are able to use the computer and types of content with which they engage online (Vaala \& Bleakley, 2015).

In analysis of 2004 data with 906 teens and their parents in the UK, Livingstone and Helsper (2008) found that parental mediation techniques were largely unrelated to teens' online behavior, though banning the social interaction features of the internet (IM/chat; email) was associated with less exposure to online risks. Sasson and Mesch (2014) found in a sample of 10-18 year old Israeli youth that social mediation was not associated with risky online activity. Mediation that included checking their child's email/online accounts or installing tracking software was actually related to participation in more online risky activities. In contrast, Kirwil (2009) examined the internet mediation practices among parents of children and adolescents across 18 European countries, as well as the self-reported exposure of their children to online risks. She found that the extent of parental mediation and the effectiveness of that mediation in shielding youth from online risks varied by country. Across most countries, "social mediation" techniques, which include co-use and the communication of rules between parents and children was generally more common and more effective than software or hardware that restricts use (i.e., "system- 
based restriction") (Vaala \& Bleakley, 2015). The conflicting evidence for the effect of parental mediation on problematic behavior makes it difficult to hypothesize a directional effect. However, we include it as a potentially important predictor.

Parental relationship quality. Research with both Asian (Chng et al., 2015) and European adolescents (Siomos et al., 2012) suggests that problematic internet use is associated with poor parental relationships. This pattern is consistent with one theory of problematic internet use that attributes the behavior to an attempt to cope with problems encountered offline, such as unsupportive peers and families (Davis, 2001). We examined this factor as a potential contributor to problematic internet use.

Accuracy of parental estimates of computer use. It is common practice to use parental reports of time their children spend with particular media (Bryant, Lucove, Evenson, \& Marshall, 2007). Parent reports may be used as estimates of media use when obtaining a child or adolescent estimate is not possible due to age and/or availability constraints associated with the research process. However, having estimates of use from both parents and adolescents in the present study allows for direct comparison of parent and adolescent estimates of time spent on the computer. In a review of studies that assessed measures of television viewing that test the relationship between parent and child report, they were well correlated with one another, but parents underestimated the amount of time their children spend watching television (Bryant et al., 2007). We expect a similar relationship for computer use.

The relative discrepancy between a parents' estimates of their adolescent's media use and the adolescent's actual use could play a role in problematic internet behaviors. In particular, we expect that adolescents who use the computer a great deal but whose parents do not know the extent of their use may be more likely to exhibit problematic internet use behaviors. This expectation is based in previous work on the relationship between parental variables and adolescent internet use (e.g., C.-H. Lin et al., 2009; Vaala \& Bleakley, 2015; Xu et al., 2012).

\section{Methods}

The purpose of the Annenberg Media Environment Survey (AMES) was to assess the media use and environment of parents and their children. Data were obtained in Spring 2012 from an online survey of 629 adolescents ages 12-17 years old and one of their parents who were members of an internet research panel maintained by the survey firm Gfk. Parent respondents were randomly selected from an online probability panel (KnowledgePanel) maintained by GfK. The panel is designed to be representative of adults (ages 18+) in the United States. GfK relies on probability-based sampling (random-digit dialing and address-based sampling) to recruit households to the panel. Households are provided with access to the internet and hardware if needed to reduce the risk of selection bias.

Of eligible parents of adolescents ( $n=1833), 49 \%$ $(n=899)$ completed the survey. Approximately $70 \%$ $(n=629)$ qualified for the sample based on their adolescents' participation and on the quality of their data as determined by GfK. Eighty percent of eligible parents gave consent for their adolescent to participate, and $98.9 \%$ of those adolescents completed the survey. Only parents whose adolescent completed the survey were included in the sample $(n=629)$. Adolescent respondents were weighted to be representative of the U.S. population ages 12-17 based on the following data from the Current Population Survey: gender, age, race/Hispanic ethnicity, census region, metropolitan area, and household income. The weights help to correct for any bias that may have occurred during the sampling process. Parental consent and teen assent was obtained for adolescent respondents. The study was approved by the Institutional Review Board at the University of Pennsylvania.

The unweighted sample of adolescents $(n=629)$ is $49.3 \%$ female with mean age of 14.8 (SD 1.64) years. Parent respondents were $58.0 \%$ female. The average parent age was 44.9 years (SD 7.06) and $83 \%$ were married. Parent education level was $33.2 \%$ high school or less, $31.2 \%$ some college, and $35.6 \%$ college graduates. The majority of parent respondents were white (68.4\%), 9.2\% were African American, 19.1 Hispanic, and $3.3 \%$ were reported as other.

\section{Measures}

Problematic internet use. Adolescents were asked to answer four questions about their internet use, irrespective of whether it was accessed through a computer or a cell phone. These items were adapted from Young's original criteria (Young, 1998) and used a 4point scale (ranging from never [0] to often [3]) as responses to how frequently adolescents had the following experiences when using the internet: (1) You stay on the internet (online) longer that you thought you would? (2) You find yourself thinking about when you will go online again? (3) You have trouble trying to cut down on the amount of time you spend online? and (4) Your grades or schoolwork have suffered because of the amount of time you spend online? A composite problematic internet use index was created for analytic purposes (Cronbach alpha $(\alpha)=0.82$; $M=1.20 S E=0.04)$. Frequencies of these items are shown in Table 1, with the distribution of the index presented in Figure 1. 


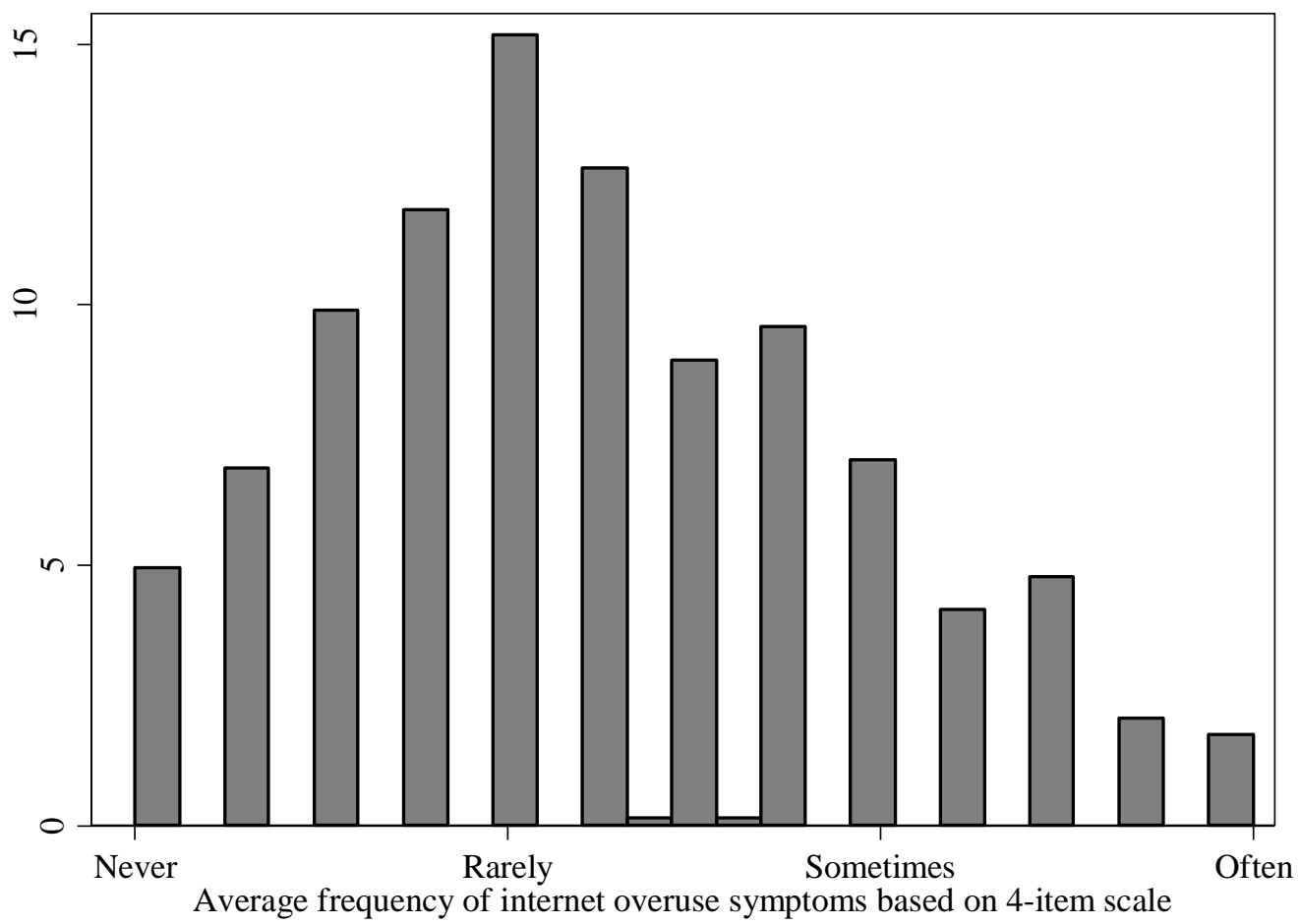

Figure 1. Distribution of problematic internet use scale (4 items, Alpha .82) (Not weighted).

Table 1. Frequencies for symptoms of problematic internet use.

\begin{tabular}{lcccc}
\hline Item & Never & Rarely & Sometimes & Often \\
\hline Stay online longer than you thought you would & $\%$ & $\%$ & $\%$ & $\%$ \\
Think about when you will go online again & 6.1 & 17.6 & 54.7 & 21.6 \\
Have trouble cutting down the amount of time you spend online & 25.7 & 37.4 & 28.0 & 9.0 \\
Grades or school have suffered because of amount of time online & 32.1 & 37.4 & 21.1 & 9.3 \\
\hline
\end{tabular}

Note: Weighted estimates.

Parents' estimates of their adolescent's computer time. Parents and adolescents were both asked about the time each adolescent spends using a computer. We asked adolescents to estimate the time they spend "using a computer" on a "typical weekday, for example last Tuesday" and on a "typical weekend day, for example last Saturday," between the time they wake up and noon, noon and $6 \mathrm{pm}$, and $6 \mathrm{pm}$ and the time they fall asleep. Computer time was defined as using a desktop, laptop, or tablet. The responses were close-ended and ranged from 0 minutes to 7 hours in 30 minute increments. The same questions were asked of parents about their adolescent's computer use. Average daily computer time was calculated by multiplying weekday viewing by 5 , weekend day viewing by 2 , summing, and dividing by 7 , representing daily computer use in hours. Thus we have two time measures: parent report of adolescent computer time and adolescent self-report of their own computer time. This time use measure is similar to others used commonly to measure parents' and children's media use (e.g., Bleakley, Jordan, \& Hennessy, 2013; Rideout et al., 2010).
Perceived parental monitoring/knowledge. Eight items were used to measure adolescents' perceived parental monitoring (Cottrell et al., 2003; Stattin \& Kerr, 2000), or the extent to which adolescents believe their parents know about their whereabouts and activities. On a scale from (1) never to (5) always, the items asked how often a parents know, for example: "what you are doing during your free time?" and "when you have an exam or paper due at school?" The mean of the items served as the measure of parental monitoring [ $\alpha=0.89 ; M=3.14, S E=0.04$ ] (Cottrell et al., 2003).

Perceived parental mediation. Mediation items were informed by Livingstone \& Helsper (2008), though inclusion of their entire 24-item measure was not possible due to space limitations and the fact that the items were being asked of adolescents rather than parents. We included items similar to those included in their "active co-use", "interaction restrictions" and "monitoring" mediation dimensions, and expanded the response options from binary to a 4-point scale from (1) never to (4) often. Adolescents were asked: "In the past 30 days, how often has a parent: "forbidden or 
blocked certain websites that you might use", "restricted the amount of time you spend online?", "monitored or tracked what you are doing online, such as tracking your Facebook page or checking your search history?", and "used the internet with you?" The mean of the 4 items was used to create the internet mediation scale ( $\alpha=0.79 ; M=2.55 S E=0.05)$.

Perceived relationship quality with parents. Four items were used to assess an adolescent's relationship quality with his or her parents. Adolescents reported how often, from never (1) to often (4), their parents: "praise you for doing well," "criticize you or your ideas," "help you do things that are important to you,", and "blame you for his/her problems." The items were averaged to create a scale $(\alpha=.72, M=: 3.34 S E=0.02)$. The criticize and blame items were recoded so that the higher the value on the scale, the better the relationship quality.

We examined the correlations among the three parental influence variables-perceived parental monitoring/knowledge, perceived parental mediation, and perceived relationship quality-to verify that they represented distinct dimensions of parental influence. Only parental monitoring and relationship quality were significantly correlated with one another $(r=0.50$, $p<.01)$. Parental mediation of internet use was not correlated with either parental monitoring $(r=0.02, \mathrm{~ns})$ or relationship quality $(r=0.03, \mathrm{~ns})$.

Covariates. We included several demographic characteristics as covariates, such as gender, race (white as referent group), and adolescent age (younger adolescent, 12-14 years; older adolescent, 15-17 years), as well as having a computer with internet access in the bedroom. Also included were sensation seeking and impulsivity, due to their association with problematic internet use in some samples (Cao, Su, Liu, \& Gao, 2007; S. S. Lin \& Tsai, 2002; Mehroof \& Griffiths, 2010). Sensation-seeking was measured using the 4 item BSSS (Hoyle, Stephenson, Palmgreen, Lorch, \& Donohew, 2002). Items were measured on a 4-point scale of strongly agree (1) to strongly disagree (2) ( $\alpha=0.78$; $M=2.27, S E=0.03$ ). Impulsivity was measured using three items from the Eysenck Impulsivity Scale (Eysenck, Pearson, Easting, \& Allsopp, 1984), asking how often, from never (0) to often (3), the adolescent reported: doing or saying things without stopping to think, getting into a jam because you do things without thinking, and thinking carefully before doing something new. $(\alpha=0.67 ;(M=1.73, S E=0.03)$.

\section{Statistical Analysis}

Variables are adolescent self-reports unless otherwise noted, when we used parental reports. Regression analyses were conducted to estimate the extent to which problematic internet use was associated with parental monitoring, parental internet mediation, pa- rental report of their adolescent's computer time, and additional covariates. We also tested an interaction between parent and adolescent report of computer time. Stata 13 was used for all analyses.

\section{Results}

Problematic internet use. The most commonly reported behavior was staying online longer than anticipated, with over $75 \%$ of the sample reporting that happened at least sometimes. Figure 1 shows the distribution of the problematic internet use scale. About $20.4 \%$ of the sample reported never or rarely engaging in all 4 of the problematic behaviors. About $32.9 \%$ reported engaging in only 1 problematic behavior either sometimes or often; $18.4 \%$ reported 2 behaviors; $17.5 \% 3$ behaviors, and $10.8 \%$ reported engaging in all 4 problem behaviors either sometimes or often. Neither age nor gender was related to the problematic internet use scale.

Parents' estimates of their adolescent's computer time. Table 2 shows both parent and adolescent reports of adolescents' computer time. The mean difference between adolescent and parent reports of time were tested using Wald tests. Parent and adolescent estimates were correlated at $r=0.69$. However, on an average day, parents underestimated the amount of time their teen spends on the computer by about 18 minutes, mostly due to underestimates of computer time in the morning and after school. The discrepancy between adolescent use estimates and parent use estimates was not associated with either parental monitoring or parental mediation.

Regression analyses. Table 3 shows the results of the regression analysis for parental influence on problematic internet use. Maximum likelihood estimation was used and unstandardized regression coefficients are reported. As shown, several perceptions about parents were related to problematic internet use. Greater parental monitoring/knowledge was related to less problematic internet use $(b=-0.21, S E=0.06, p<.01)$, as was parental mediation of internet use $(b=-0.09$, $S E=0.04, p<05)$ and parental relationship quality $(b=-$ $0.18, S E=.07, p<01)$. Time spent using a computer, as estimated by adolescents, was positively associated with problematic internet use $(b=0.07, S E=0.02, p<01)$; parent report of their teen's computer time was not related to problematic internet use.

An interaction term between parent and adolescent time estimates was added to the regression to determine if symptoms of problematic internet use were more likely in instances in which parents and adolescent reports did not coincide. The interaction was statistically significant; see Figure 2 for a graph of the interaction.

Adolescents who spent more time with computers were more likely to exhibit problematic internet use when their parents estimated they spent less than 2 
hours a day (below the median) compared to those adolescents who spent more time with computer but whose parents estimates were higher and therefore more closely aligned with their own. This suggests that parental accuracy in terms of time spent on the computer is related to the likelihood of problematic internet behaviors. The difference or discrepancy between parental and adolescent reports was not correlated with parental monitoring/knowledge $(r=0.02, n s)$, pa- rental mediation ( $r=0.07, \mathrm{~ns})$ or relationship quality ( $r=0.03$, ns).

There were also some demographic differences. African American teens were less likely to report problematic internet use than their white peers $(b=0.20$, $S E=.03, p<.05)$, and greater impulsivity was also associated with more problematic use $(b=0.21, S E=.06$, $p<.01)$.

Table 2. Weighted parent and adolescent reports of adolescents' hours spent with television, video games, and computer on weekdays and weekends, by time of day.

\begin{tabular}{|c|c|c|}
\hline & $\begin{array}{l}\text { Parent report } \\
(\mathrm{n}=629)\end{array}$ & $\begin{array}{l}\text { Adolescent report } \\
(n=629)\end{array}$ \\
\hline & Mean (SE) & Mean (SE) \\
\hline \multicolumn{3}{|l|}{ Computer use } \\
\hline \multicolumn{3}{|l|}{ Weekday } \\
\hline AM & $0.53(.06)$ & $1.23(.07)^{* * *}$ \\
\hline Midday & $0.82(.05)$ & $1.05(.06)^{* *}$ \\
\hline PM & $1.12(.05)$ & $1.01(.05)$ \\
\hline Average weekday & $2.44(.12)$ & $3.27(.15)^{* * *}$ \\
\hline \multicolumn{3}{|l|}{ Weekend day } \\
\hline AM & $0.74(.04)$ & $0.80(.06)$ \\
\hline Midday & $1.06(.06)$ & $1.08(.06)$ \\
\hline PM & $1.08(.07)$ & $1.07(.06)$ \\
\hline Average weekend day & $2.86(.15)$ & $2.92(.16)$ \\
\hline Average day & $2.59(.12)$ & $3.17(.14)^{* *}$ \\
\hline
\end{tabular}

Table 3. Effects of parental environment and media access on problematic internet use among 12-17 year old adolescents $(n=595)$.

\begin{tabular}{|c|c|}
\hline Adolescent sample & b (SE) \\
\hline \multicolumn{2}{|l|}{ Parent variables } \\
\hline Parental monitoring & $-0.15(.06)$ \\
\hline Parental mediation (internet) & $-0.09(.04)$ \\
\hline Relationship quality & $-0.18(.07)$ \\
\hline \multicolumn{2}{|l|}{ Media time and access variables } \\
\hline Bedroom computer with internet access & $0.004(.07)$ \\
\hline Average daily time (hours) spent using a computer-adolescent report & $0.06(.02)$ \\
\hline Average daily time (hours) spent using a computer - parent report & $0.01(.02)$ \\
\hline \multicolumn{2}{|l|}{ Demographic and personality variables } \\
\hline Child gender (Female) & $0.04(.06)$ \\
\hline Child age & $-0.002(.02)$ \\
\hline \multicolumn{2}{|l|}{ Parent race (referent: White) } \\
\hline African American & $-0.19(.09)$ \\
\hline Hispanic & $-0.03(.08)$ \\
\hline Other & $0.04(.21)$ \\
\hline Sensation seeking & $0.08(.05)$ \\
\hline Impulsivity & $0.21(.06)$ \\
\hline Interaction: Adolescent report of time * Parent report of time & $-0.01(.00)$ \\
\hline
\end{tabular}

Note: Bolded values are statistically significant at $p<.05$. The unstandardized regression coefficients reported in this table were estimated prior to inclusion of the interaction term. 


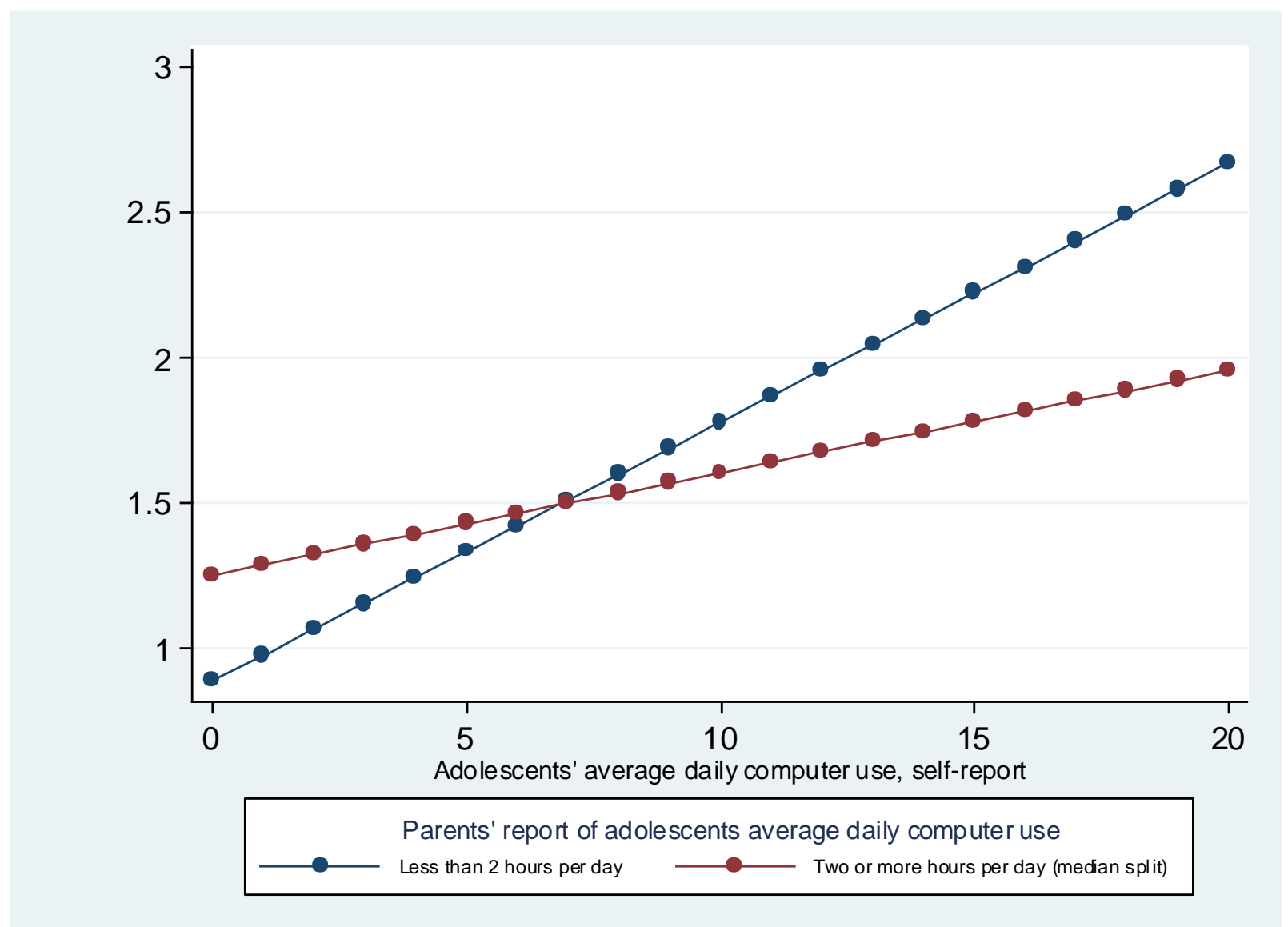

Figure 2. Interaction of parent and adolescent time estimates of computer use on problematic internet use. Note: A median split is used for graphing purposes. Both variables were treated as continuous in the interaction term. This graph is based on unweighted data.

\section{Discussion}

The internet and its various uses are featured prominently in the media lives of youth. Accompanying their use is a concern about misuse and/or overuse of the internet in ways that would be considered problematic. In a national sample of adolescents from the United States, we found that some symptoms of problematic internet use are quite common (i.e., staying online longer than anticipated), especially among white youth, but only about $10 \%$ of the sample reported any occurrence of all 4 problematic behaviors. However, parental monitoring, parental mediation, and better relationship quality were associated with less problematic use, and parents' perceptions of their adolescent's time also mattered for some teens as well.

These results provide evidence that problematic internet use is associated with potentially modifiable home environment factors. Parental monitoring, for instance, is consistently associated with less risky behavior (e.g., Borawski et al., 2003) and media use (e.g. Vaala \& Bleakley, 2015). Among this sample of youth, teens who reported increased parental monitoring was less likely to report problematic internet behaviors. However, parental monitoring as perceived by the ado- lescent is often considered to be an indicator of an adolescent's willingness to disclose information about their lives (Kerr et al., 2010; Stattin \& Kerr, 2000), and this view is supported by the moderate correlation between parental monitoring and perceived relationship quality. There was a similar relationship with parental mediation activities, as parents who monitor their adolescents' media use and time may have greater concerns about media in general. Youth who reported increased mediation, which included blocking certain websites, restricting time, tracking internet use and couse of the internet, were also less likely to report problematic behaviors. This is consistent with some studies (Khurana, et al., 2014; Kirwil, 2009; Livingstone \& Helsper, 2008) but not with others that found some mediation strategies to be associated with a greater amount of online risky activities (Sasson \& Mesch, 2014). Better parental relationship quality was also associated with fewer symptoms of problematic internet use. Overall, these findings suggest that adolescents engaging in problematic internet use live in families with less connection to and support from parents. It could be that youth who have poorer relationships with their parents turn to the internet to compensate, or that problematic use weakens or strains the parent-teen relationship. 
Unlike parental monitoring, mediation, or relationship quality, parental estimates of their adolescents' report of their time spent with a computer was not significantly associated with problematic internet use. Instead, parent estimates were only relevant to problematic internet use in instances when adolescents spent more time with a computer than their parents estimated (i.e., their parents underestimated their time). It is unclear what a parent's underestimate represents. Post hoc analysis suggested that the differences between parental and adolescent estimates were not significantly correlated with either adolescent or parent reports of parental monitoring, parental mediation, or relationship quality. Thus, this predictor appears to reflect a general lack of awareness of the teen's computer use. Essentially, it seems that adolescents in homes in which parents engage in less monitoring, less mediation, have a strained relationship with their teen, or are unaware of their teen's excessive computer use are exhibiting more problematic internet behaviors.

Limitations. As with any cross-sectional survey, the direction of the relationships between parental influences and adolescent internet use cannot be determined. Additionally, although the items used to measure problematic internet use were adapted from a standard measure of internet addiction (Young, 1998), without a more comprehensive measure we may be missing key aspects of the construct that could be related to parental influences differently than the relationships we have described here. More research, especially longitudinal designs, are needed to more fully understand the relationships between these variables. The use of self-report to measure problematic internet use, although a common practice, is a limitation as well. Adolescents may not recognize their own problematic behavior as assessed with these measures, or may have over inflated notions about what is problematic, resulting in over or under estimates of problematic use. Finally, although we asked participants about their internet behaviors, encompassing access by both computer and mobile phone, we did not compare the two access points. Smartphones may make it easier for adolescents to access the internet at all times of day and with less parental intervention than computers, and this possibility only grows with the popularity of smartphones. Future research may wish to compare the current findings for internet use on computers and phones.

Conclusion. Problematic internet use is often linked to a myriad of negative psychological, interpersonal, and academic outcomes for adolescents and emerging adults (Caplan \& High, 2011; Choi et al., 2009; Jacobsen \& Forste, 2011; Ko et al., 2008; Yoo et al., 2004). It is important to understand what conditions are associated with problematic internet use in order to understand how to reduce its prevalence and effects. The present work focused on parental variables such as monitoring, mediation, relationship quality, and accu- racy of time estimates to explore how the parental and home context may be related to adolescent problematic internet use. As expected, perceived parental monitoring and mediation of internet use are associated with reduced problematic internet use, as was a better parent-teen relationship. In addition, adolescents who report high computer use but whose parents underestimate their use reported more problematic internet use. These results suggest that the relationship between parents and their teen is an important factor in understanding adolescent problematic internet use and that parents may both reduce as well as contribute to problematic adolescent internet use.

\section{Acknowledgments}

The authors would like to thank the Annenberg Public Policy Center for their support of this survey.

\section{Conflict of Interests}

The authors declare no conflict of interests.

\section{References}

American Psychiatric Association. (2013). DSM 5: Diagnostic and statistical manual of mental disorders. Arlington: American Psychiatric Association.

Aoyama, I., Barnard-Brak, L., \& Talbert, T. (2012). Cyberbullying among high school students: Cluster analysis of sex and age differences and the level of parental monitoring. Evolving Psychological and Educational Perspectives on Cyber Behavior, 246.

Bleakley, A., Jordan, A. B., \& Hennessy, M. (2013). The relationship between parents' and children's television viewing. Pediatrics, 132(2), 364-371.

Bleakley, A., Vaala, S. E., Jordan, A., \& Romer, D. (2014). The Annenberg media environment survey: Media access and use in U.S. homes with children and adolescents. In A. Jordan \& D. Romer (Eds.), Media and the well-being of children and adolescents. (pp. 119). New York: Oxford University Press.

Borawski, E. A., levers-Landis, C. E., Lovegreen, L. D., \& Trapl, E. S. (2003). Parental monitoring, negotiated unsupervised time, and parental trust: The role of perceived parenting practices in adolescent health risk behaviors. Journal of Adolescent Health, 33(2), 60-70.

Bryant, M., Lucove, J., Evenson, K., \& Marshall, S. (2007). Measurement of television viewing in children and adolescents: A systematic review. Obesity Reviews, 8(3), 197-209.

Cao, F., Su, L., Liu, T., \& Gao, X. (2007). The relationship between impulsivity and Internet addiction in a sample of Chinese adolescents. European Psychiatry, 22(7), 466-471.

Caplan, S. E., \& High, A. C. (2011). Online social interac- 
tion, psychosocial well-being, and problematic internet use. In K. S. Young \& C. Abreu (Eds.), Internet addiction: $A$ handbook and guide to evaluation and treatment (pp. 35-53).

Chng, G. S., Li, D., Liau, A. K., \& Khoo, A. (2015). Moderating effects of the family environment for parental mediation and pathological internet use in youths. Cyberpsychology, Behavior, and Social Networking, 18(1), 30-36.

Cho, C.-H., \& Cheon, H. J. (2005). Children's exposure to negative Internet content: Effects of family context. Journal of Broadcasting \& Electronic Media, 49(4), 488-509.

Choi, K., Son, H., Park, M., Han, J., Kim, K., Lee, B., \& Gwak, H. (2009). Internet overuse and excessive daytime sleepiness in adolescents. Psychiatry and Clinical Neurosciences, 63(4), 455-462.

Clark, L. S. (2009). Digital media and the generation gap: Qualitative research on US teens and their parents. Information, Communication \& Society, 12(3), 388407.

Cottrell, L., Li, X., Harris, C., D'Alessandri, D., Atkins, M., Richardson, B., \& Stanton, B. (2003). Parent and adolescent perceptions of parental monitoring and adolescent risk involvement. Parenting: Science and Practice, 3(3), 179-195.

Davis, R. A. (2001). A cognitive-behavioral model of pathological Internet use. Computers in Human Behavior, 17(2), 187-195.

DiClemente, R. J., Wingood, G. M., Crosby, R., Sionean, C., Cobb, B. K., Harrington, K., . . . Oh, M. K. (2001). Parental monitoring: Association with adolescents' risk behaviors. Pediatrics, 107(6), 1363-1368.

Douglas, A. C., Mills, J. E., Niang, M., Stepchenkova, S., Byun, S., Ruffini, C., . . . Atallah, M. (2008). Internet addiction: Meta-synthesis of qualitative research for the decade 1996-2006. Computers in human behavior, 24(6), 3027-3044.

Durkee, T., Kaess, M., Carli, V., Parzer, P., Wasserman, C., Floderus, B., . . . Bobes, J. (2012). Prevalence of pathological internet use among adolescents in Europe: demographic and social factors. Addiction, 107(12), 2210-2222.

Griffiths, M. (2005). A 'components' model of addiction within a biopsychosocial framework. Journal of Substance Use, 10(4), 191-197.

Hoyle, R. H., Stephenson, M. T., Palmgreen, P., Lorch, E. P., \& Donohew, R. L. (2002). Reliability and validity of a brief measure of sensation seeking. Personality and Individual Differences, 32(3), 401-414.

Huebner, A. J., \& Howell, L. W. (2003). Examining the relationship between adolescent sexual risk-taking and perceptions of monitoring, communication, and parenting styles. Journal of Adolescent Health, 33(2), 7178.

Jacobsen, W. C., \& Forste, R. (2011). The wired generation: Academic and social outcomes of electronic media use among university students. Cyberpsychology, Behavior, and Social Networking, 14(5), 275280.

Kerr, M., Stattin, H., \& Burk, W. J. (2010). A reinterpretation of parental monitoring in longitudinal perspective. Journal of Research on Adolescence, 20(1), 3964.

Khurana, A., Bleakley, A., Jordan, A. B., \& Romer, D. (2014). The protective effects of parental monitoring and internet restriction on adolescents' risk of online harassment. Journal of Youth And Adolescence, 44(5), 1039-1047.

Kirwil, L. (2009). Parental mediation of children's internet use in different European countries. Journal of Children and Media, 3(4), 394-409.

Ko, C.-H., Yen, J.-Y., Yen, C.-F., Chen, C.-S., Weng, C.-C., \& Chen, C.-C. (2008). The association between internet addiction and problematic alcohol use in adolescents: The problem behavior model. CyberPsychology \& Behavior, 11(5), 571-576.

Kubey, R. W., Lavin, M. J., \& Barrows, J. R. (2001). Internet use and collegiate academic performance decrements: Early findings. Journal of Communication, 51(2), 366-382.

Li, X., Stanton, B., \& Feigelman, S. (2000). Impact of perceived parental monitoring on adolescent risk behavior over 4 years. Journal of Adolescent Health, 27(1), 49-56.

Lin, C.-H., Lin, S.-L., \& Wu, C.-P. (2009). The effects of parental monitoring and leisure boredom on adolescents' internet addiction. Adolescence, 44(176), 9931004.

Lin, S. S., \& Tsai, C.-C. (2002). Sensation seeking and internet dependence of Taiwanese high school adolescents. Computers in Human Behavior, 18(4), 411 426.

Livingstone, S., \& Bober, M. (2004). UK Children go online: Surveying the experiences of young people and their parents. London: LSE Research Online.

Livingstone, S., \& Helsper, E. J. (2008). Parental mediation of children's internet use. Journal of Broadcasting \& Electronic Media, 52(4), 581-599.

Madden, M., Lenhart, A., Duggan, M., Cortesi, S., \& Gasser, U. (2013). Teens and technology 2013. Washington: Pew Internet \& American Life Project.

Mehroof, M., \& Griffiths, M. D. (2010). Online gaming addiction: the role of sensation seeking, self-control, neuroticism, aggression, state anxiety, and trait anxiety. Cyberpsychology, Behavior, and Social Networking, 13(3), 313-316.

Mesch, G. S. (2009). Parental mediation, online activities, and cyberbullying. CyberPsychology \& Behavior, 12(4), 387-393.

Mitchell, P. (2000). Internet addiction: Genuine diagnosis or not? The Lancet, 355(9204), 632.

Moreno, M. A., Jelenchick, L., Cox, E., Young, H., \& Christakis, D. A. (2011). Problematic internet use 
among US youth: A systematic review. Archives of Pediatrics \& Adolescent Medicine, 165(9), 797-805.

Nathanson, A. I. (2002). The unintended effects of parental mediation of television on adolescents. Media Psychology, 4(3), 207-230.

Racz, S. J., \& McMahon, R. J. (2011). The relationship between parental knowledge and monitoring and child and adolescent conduct problems: A 10-year update. Clinical Child and Family Psychology Review, 14(4), 377-398.

Rideout, V., Foehr, U., \& Roberts, D. (2010). Generation M2: Media in the lives of 8 to 18 year olds. California: Kaiser Family Foundation.

Sasson, H., \& Mesch, G. (2014). Parental mediation, peer norms and risky online behavior among adolescents. Computers in Human Behavior, 33, 32-38.

Siomos, K., Floros, G., Fisoun, V., Evaggelia, D., Farkonas, N., Sergentani, E., . . Geroukalis, D. (2012). Evolution of Internet addiction in Greek adolescent students over a two-year period: the impact of parental bonding. European child \& adolescent psychiatry, 21(4), 211-219.

Smith, A. (2014). African Americans and techonology use: A demographic portrait. Retrieved from http://www.pewinternet.org/files/2014/01/AfricanAmericans-and-Technology-Use.pdf

Stattin, H., \& Kerr, M. (2000). Parental monitoring: A reinterpretation. Child Development, 71(4), 1072-1085.

Sun, P., Unger, J. B., Palmer, P. H., Gallaher, P., Chou, C.P., Baezconde-Garbanati, L., . . . Johnson, C. A.
(2005). Internet accessibility and usage among urban adolescents in Southern California: implications for web-based health research. CyberPsychology \& Behavior, 8(5), 441-453.

Tsitsika, A., Janikian, M., Schoenmakers, T. M., Tzavela, E. C., Ólafsson, K., Wójcik, S., . . . Richardson, C. (2014). Internet Addictive Behavior in Adolescence: A Cross-Sectional Study in Seven European Countries. Cyberpsychology, Behavior, and Social Networking.

Vaala, S. E., \& Bleakley, A. (2015). Monitoring, mediating, and modeling: Parental influence on adolescent computer and internet use in the United States. Journal of Children and Media, 9(1), 40-57.

Valkenburg, P. M., Krcmar, M., Peeters, A. L., \& Marseille, N. M. (1999). Developing a scale to assess three styles of television mediation:"Instructive mediation," "restrictive mediation," and "social coviewing". Journal of Broadcasting \& Electronic Media, 43(1), 52-66.

Xu, Z., Turel, O., \& Yuan, Y. (2012). Online game addiction among adolescents: Motivation and prevention factors. European Journal of Information Systems, 21(3), 321-340.

Yoo, H. J., Cho, S. C., Ha, J., Yune, S. K., Kim, S. J., Hwang, J., . . . Lyoo, I. K. (2004). Attention deficit hyperactivity symptoms and internet addiction. Psychiatry and clinical neurosciences, 58(5), 487-494.

Young, K. S. (1998). Internet addiction: The emergence of a new clinical disorder. CyberPsychology \& Behavior, 1(3), 237-244.

\section{About the Authors}

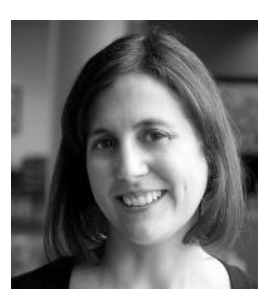

\section{Dr. Amy Bleakley}

Amy Bleakley, PhD, MPH, is a senior research scientist at the Annenberg School for Communication at the University of Pennsylvania. Her research focuses on investigating media effects on youth health risk behaviors and health message development and testing.

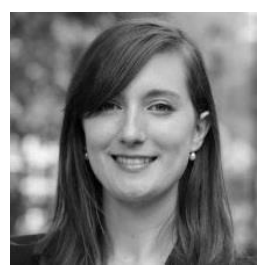

\section{Dr. Morgan E. Ellithorpe}

Morgan E. Ellithorpe, PhD, is the Martin Fishbein Postdoctoral Fellow in the Annenberg School for Communication at the University of Pennsylvania. Her areas of research include media psychology and media effects in the areas of health and risk, stereotyping and prejudice, and moral behavior.

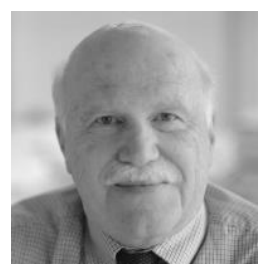

\section{Dr. Daniel Romer}

Daniel Romer, PhD, is the Director of Research at the Annenberg Public Policy Center of the University of Pennsylvania. His research focuses on policy relevant effects of the media and other social influences on the behavioral and mental health of adolescents. 